\title{
The Effect of Lay Length on the Antipull Performance of Steel Cords and the Spinning Loss Based on the FEM
}

\author{
Lin Lu, ${ }^{1,2,3,4}$ Zhuxin Chen $\mathbb{D}^{1},{ }^{1}$ Lili Yao, ${ }^{2,3}$ Jie Zhou, ${ }^{2,3}$ Feng Xue $\mathbb{D}^{4},{ }^{4}$ and Hongwu Song ${ }^{5}$ \\ ${ }^{1}$ School of Materials Science and Engineering, Shenyang University, Shenyang 110044, China \\ ${ }^{2}$ Jiangsu Key Laboratory for Structural and Functional Metal Composite Materials, Taizhou 225721, China \\ ${ }^{3}$ Jiangsu Xingda Steel Tyre Cord Co., Ltd, Taizhou 225721, China \\ ${ }^{4}$ School of Materials Science and Engineering, Southeast University, Nanjing 211189, China \\ ${ }^{5}$ Institute of Metal Research, Chinese Academy of Sciences, Shenyang 110016, China \\ Correspondence should be addressed to Zhuxin Chen; 412748767@qq.com
}

Received 23 September 2021; Revised 29 December 2021; Accepted 31 December 2021; Published 25 January 2022

Academic Editor: Tomasz Trzepieciński

Copyright ( 2022 Lin Lu et al. This is an open access article distributed under the Creative Commons Attribution License, which permits unrestricted use, distribution, and reproduction in any medium, provided the original work is properly cited.

\begin{abstract}
This paper is mainly aimed at $0.28+6 \times 0.26$ steel cords and $0.26+6 \times 0.24$ steel cords under different lay length conditions through the ABAQUS finite element analysis software to limit the tensile performance of the steel cord and the stress field distribution during the tensile loading. Based on the finite meta-analysis, in this experiment, the tensile simulation of the same kind of steel cord at the twist lay length of $5 \mathrm{~mm}, 7 \mathrm{~mm}, 9 \mathrm{~mm}, 11 \mathrm{~mm}, 13 \mathrm{~mm}$, and $15 \mathrm{~mm}$ was carried out under the condition of $2 \mathrm{~mm} / \mathrm{s}$. The results show that, under certain conditions of other process conditions, with the increase of the twisting distance of the steel cord strands, the strength of the steel cord increases, the deformability decreases, the stress concentration decreases, and the spinning loss decreases. The spinning loss formula is modified to reduce the calculation error.
\end{abstract}

\section{Introduction}

Steel cords are usually used as meridian tire skeleton structures and play an important role in improving tire strength, performance, and service life [1-3]. As a meridian tire skeleton structure, the performance of steel cords is critical for meridian tires, so the improvement of steel cord performance is also the focus of close attention of related enterprises [4-6]. Steel cord originated in the steel wire rope cable and other industries, in the processing process and structure there is a certain similarity.In the development of steel cord, steel cord to repeated experiments and other ways to obtain the optimal structural parameters, so the experimental direction is poor, consumption time is longand results in waste of resources [7-9]. Finite element analysis is widely used in mechanical structural analysis and has a more intuitive and obvious effect on stress analysis of complex structural metal products such as steel cords.
In 2003, Wang et al. $[10,11]$ derived the structural parameter equation of the secondary twisted steel cord based on the Frenet-Serret formula. From 2010 to 2011, Erdonmez and Imark [12-14] used MATLAB computer language to complete the modeling of the primary and secondary twisting structures of steel cords by means of codes, and combined HyperMesh and ABAQUS software for mesh rendering and mechanical finite element analysis. Wang et al. $[15,16]$ summarized three modeling methods including three-dimensional drawing software and modeling equation combined modeling, using the sweeping method for modeling, and mathematical software combined with three-dimensional drawing software modeling. Then, the data envelopment analysis method was introduced into the steel cord modeling analysis. In 2017, Xiang et al. [17] used 3D digital image correlation (3D DIC) technology to extract surface stress and strain data of steel cords and found that the rotation and restriction of both ends of the steel cord would increase the contact stress between strands. In 2018, 
Long et al. [9] analyzed the factors affecting the steel cord conveyor belt and analyzed the influence of different positions and arrangement sequences of the steel cord in the conveyor belt on the strength of the contact interface between the steel cord and the rubber. The pulling force is slightly greater than the edge position. The drawing force increases nonlinearly with the increase in the number of strands. In 2019, Li et al. [18] analyzed the influence of steel cord length, wire diameter, rubber thickness, and the number of internally distributed steel cords on the drawing force of the steel cord conveyor belt joint. Among them, the strength of steel cord length and diameter of the influence is closer to linearity, and the influence of the number of steel cords on the strength of the joint shows a nonlinear increase. In 2021, Olchówka et al. [19] used the DiagBelt system to scan two-dimensional images of magnetic field changes around faults to identify defects in steel cord production and applied artificial intelligence methods to build multilayer neural networks (MLP) and teach them appropriate damage recognition. This analysis can determine the Pearson linear correlation coefficient between the parameter being changed and the fault image.

In this paper, the finite element method is used to determine the internal stress distribution and spinning loss state of the steel cord under different lay length conditions to improve the performance of the steel cord. It is attempted to analyse the force distribution of steel cord core and surface strands and the trend of maximum load through ABAQUS finite element analysis software for the stretch load of steel cords under different lay length conditions. The steel cord model is made of $0.28+6 \times 0.26(0.28 \mathrm{~mm}$ diameter single wire with 6 surface strands, $0.26 \mathrm{~mm}$ diameter monofilament) steel cord, and $0.26+6 \times 0.24$ (center strand is $0.26 \mathrm{~mm}$ diameter monofilament, surface strands of the wire is $60.24 \mathrm{~mm}$ diameter single wire) steel cord, through the ABAQUS software model building module for steel cord 3D model drawing and the use of ABAQUS finite element analysis section for $0.28+6 \times 0.26$ steel cord and $0.26+6 \times 0.24$ steel cord at $2 \mathrm{~mm} / \mathrm{s}$ stretch simulation under conditions.

\section{Experimental Method}

2.1. Experimental Process. The material mechanics performance test of the single wire that makes up the steel cord is carried out to provide the parameters required for the simulation and to verify the accuracy of the simulation process method. The 6 sets of finite element analysis tests with different spacing of $0.26+6 \times 0.24,0.28+6 \times 0.26$ are then carried out to analyse the effect on the stretching performance of steel cords with the change of steel cord lay length, as shown in Figure 1.

2.2. The Establishment of a Finite Element Model. The steel cord structure usually contains a wire strand structure with one, two, three, or even multiple twists [20], and this experiment mainly analyses one of the strands in detail, and the main involved structural form can be determined by the following parameters, including the steel cord core single wire radius $r_{0}$, the face single wire radius $r 1$, the tingling radius $R$, and the lay length $P$, as shown in Figure 2 [21-24]. Wherein in the simulation process, $0.28+6 \times 0.26$ steel cord core single wire diameter $r_{0}=0.28 \mathrm{~mm}, r_{1}=0.26 \mathrm{~mm}$, the twisting radius $R=0.27 \mathrm{~mm}$, the center line length $S=20 \mathrm{~mm}$, and $0.26+6 \times 0.24$ steel cord core single wire diameter $r_{0}=0.26 \mathrm{~mm}, r_{1}=0.24 \mathrm{~mm}$, the twisting radius $R=0.25 \mathrm{~mm}$, centerline length $S=20 \mathrm{~mm}$, lay length is, respectively, set to $P=5 \mathrm{~mm}, 7 \mathrm{~mm}, 9 \mathrm{~mm}, 11 \mathrm{~mm}, 13 \mathrm{~mm}$, and $15 \mathrm{~mm}$ for comparative testing.

The stretching simulation of steel cords in finite element analysis software involves only one-time twist structure, so the model uses only one-time fabric model building blocks in ABAQUS finite element analysis software and can build the required models and assign material properties required for stretch analysis of the model cross section, including material density and single-wire elasticity of different silk diameters (Yang's modulus, Poisson ratio), and plasticity (plastic strength, plastic deformation). In order to make the steel cord finite element analysis process consistent with the steel cord tensile performance test process as much as possible, a $5 \mathrm{~mm}$ length MPC constraint (beam) was applied to both ends of the steel cord through the reference point, and according to the tensile test process, using a dynamic explicit analysis step, a completely fixed boundary condition is applied to one end of the rope, and the other end is stretched at a constant speed of $2 \mathrm{~mm} / \mathrm{s}$ in the stretching direction.

The main mechanical properties of steel cords are shown in the ability to withstand pull out in order to perform mechanical finite element analysis on the steel cord model; therefore, the mesh type uses a 3D stress mesh (C3D8R: an 8 node linear brick, reduced integration, and hourglass control), and steel cord is a spiral cylindrical structure. Common element shapes such as hexahedron, tetrahedron, and wedge-shaped mesh can effectively divide the steel cord model. In order to make the finite element analysis more efficient, this experiment mainly uses hexahedral mesh. The model, standard element library, and linear geometric order analysis are divided because of the randomness of the steel cord break cross-sectional position, so the mesh seed is evenly distributed in the direction of stretching, and each layer section evenly distributed hexagonal mesh 32 units, as shown in Figure 3.

The mesh quality is analysed, and shape inspection is performed according to quad-face corner angle: 10 160, aspectratio $\$ 10$; geometric eccentricity factor $\$ 0.2$, and side length $0.01 \sim 1$ for size inspection, and the results are shown in Table 1.

The interaction between steel cords is defined by the common contact mechanism in ABAQUS, and the method between the strands of steel cords is used in the form of hard contact upward, and the tangent is defined by the penalty to determine the effect of friction on the simulation, and the coefficient of friction is valued at 0.3 . The force generated by the different strands in the steel cord during the contact process constitutes friction so as to realize the mechanical contact between the strands. 


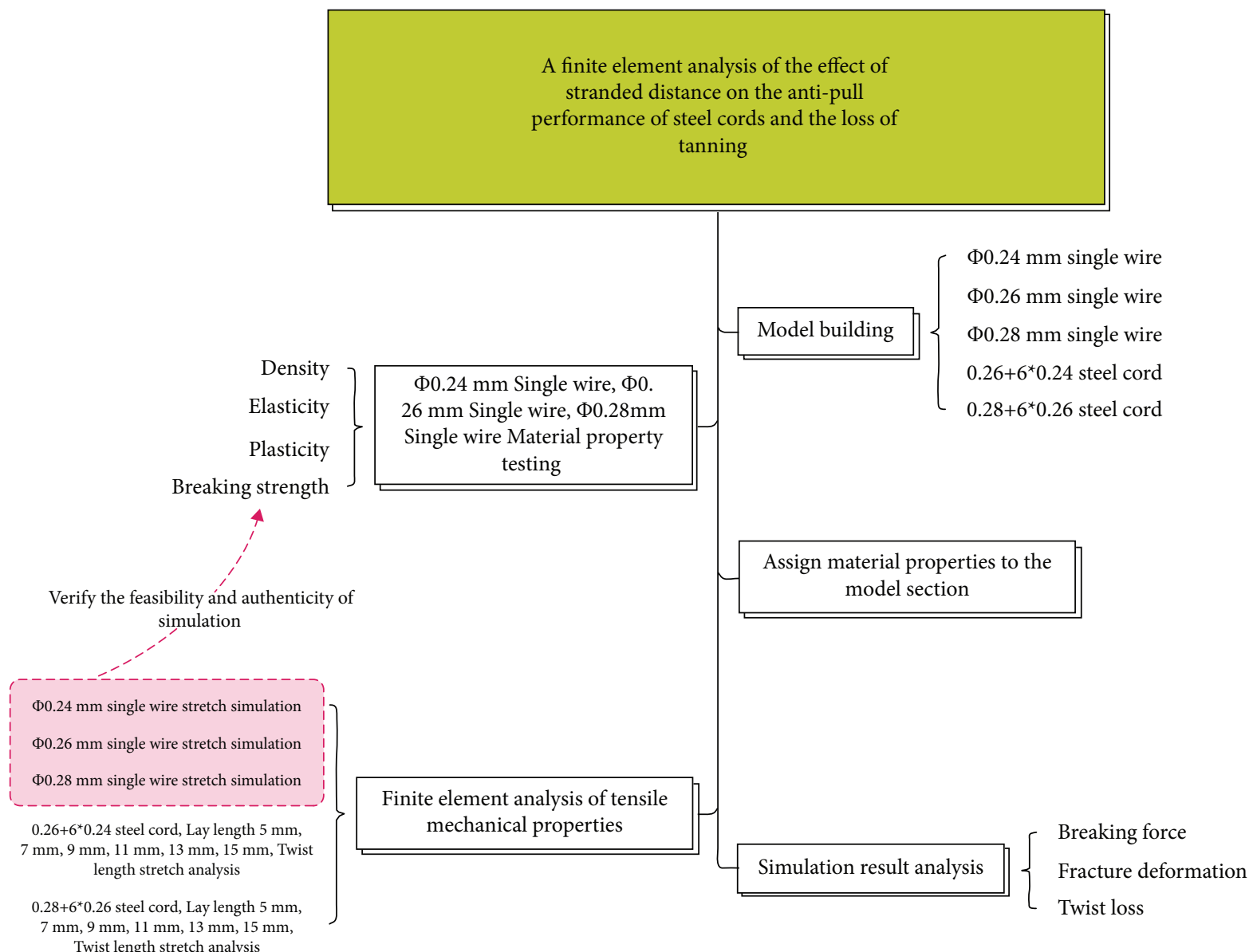

Figure 1: Experimental process.
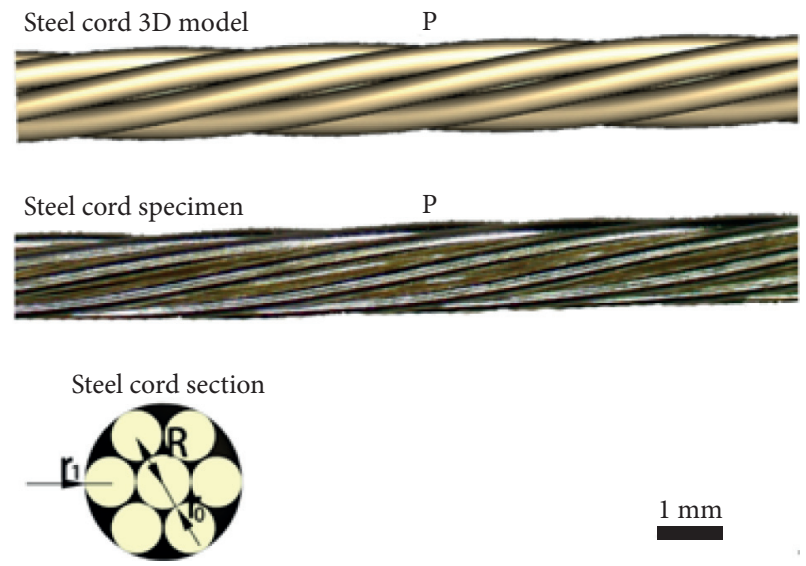

Figure 2: Steel cord model and specimen parameters.

Material selection: 72A material, material properties related to density: $7.81 \mathrm{E}-09$ tonne $/ \mathrm{mm}^{3}$, Young's modulus: $206000 \mathrm{MPa}$, Poisson's datio: 0:3, and $\Phi 0.24 \mathrm{~mm}, \Phi 0.26 \mathrm{~mm}$, and $\Phi 0.28 \mathrm{~mm}$ steel cord single wire stretch stress strain curve and break force are determined by stretch testing. The tested single-wire stretching performance is shown in Table 2 below, and the stress-strain curve is shown in Figure 4 below, and then, the material properties are attached to the model cross section to complete the granting of material properties.

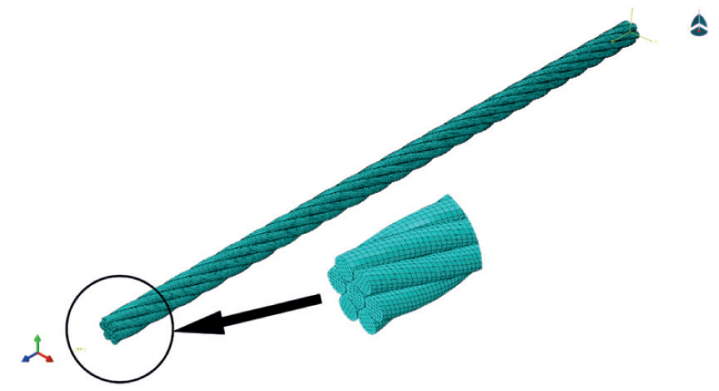

FIGURE 3: Finite element meshing model.

\section{Results and Discussion}

3.1. Steel Cord Simulation Results. $2 \mathrm{~mm} / \mathrm{s}$ speed stretch simulation of $\Phi 0.24 \mathrm{~mm}, \Phi 0.26 \mathrm{~mm}$, and $\Phi 0.28 \mathrm{~mm}$ steel cord single wire of steel cord was used to obtain the steel cord simulation break force, tensile strength, and total elongation, as shown in Table 3 below. By comparing Table 2 with Table 3, it can be seen that the stretch properties of steel cords obtained from the simulation results are the same as the actual measurements, which also shows that the test scheme; that is, the different lay lengths carried out by ABAQUS finite element analysis software are $0.26+6 \times 0.24$ steel cords and $0.28+6 \times 0.26$ steel cords. The finite element 
TABLE 1: Mesh quality analysis.

\begin{tabular}{lcc}
\hline & Center strand & Surface strand \\
\hline Hex elements & 12864 & 14400 \\
Min angle on quad faces $<10$ & $0(0 \%)$ & $0(0 \%)$ \\
Average min angle on quad faces & 75.27 & 76.01 \\
Worst min angle on quad faces & 69.81 & 62.69 \\
Max angle on quad faces $>160$ & $0(0 \%)$ & $0(0 \%)$ \\
Average max angle on quad faces & 109.60 & 105.66 \\
Worst max angle on quad faces & 123.63 & $0(0 \%)$ \\
Aspect ratio $>10$ & 1.48 & $0(0 \%)$ \\
Average aspect ratio & 1.90 & 1.62 \\
Worst aspect ratio & $0(0 \%)$ & 2.07 \\
Geometric deviation factor $>0.2$ & 0.0485 & $0(0 \%)$ \\
Average geometric deviation factor & 0.0565 & 0.0435 \\
Worst geometric deviation factor & $0(0 \%)$ & 0.0599 \\
Min edge length $<0.01$ & 0.0358 & $0(0 \%)$ \\
Average min edge length & 0.0275 & 0.0333 \\
Shortest edge & $0(0 \%)$ & 0.0241 \\
Max edge length $>1$ & 0.0519 & $0(0 \%)$ \\
Average max edge length & 0.0581 & 0.0524 \\
Longest edge & $0(0 \%)$ & 0.0661 \\
Analysis errors & $0(0 \%)$ & $0(0 \%)$ \\
Analysis warnings & $0(0 \%)$ \\
\hline
\end{tabular}

TABle 2: Single-wire stretch performance.

\begin{tabular}{lcccc}
\hline Theoretical silk path $(\mathrm{mm})$ & Measured wire diameter $(\mathrm{mm})$ & Breaking force $(\mathrm{N})$ & Tensile strength (mpa) & Total elongation Ag $(\%)$ \\
\hline 0.24 & 0.241 & 160.97 & 3560 & 2.419 \\
0.26 & 0.260 & 182.81 & 3445 & 2.669 \\
0.28 & 0.279 & 213.25 & 3465 & 2.288
\end{tabular}

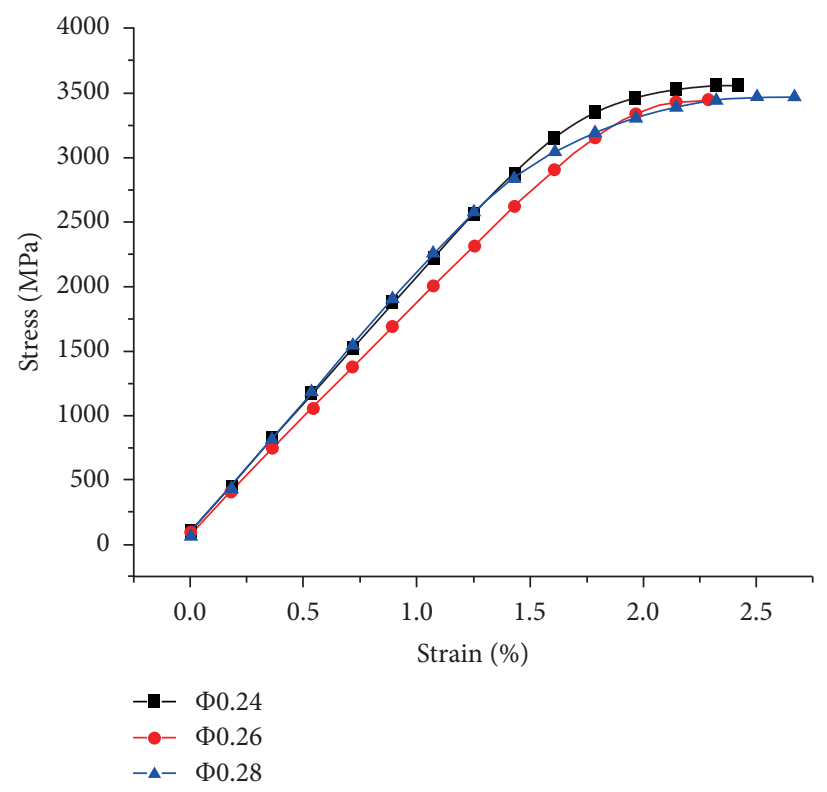

FIGURE 4: Steel cord single wire stress-strain curve.

TABLe 3: Single-silk stretch performance simulation values.

\begin{tabular}{lccc}
\hline Silk path $(\mathrm{mm})$ & Breaking force $(\mathrm{N})$ & Tensile strength $(\mathrm{mpa})$ & Total elongation Ag $(\%)$ \\
\hline 0.24 & 158.58 & 3507 & 2.3 \\
0.26 & 180.31 & 3398 & 2.2 \\
0.28 & 211.04 & 3429 & 2.4 \\
\hline
\end{tabular}


analysis process has a certain degree of authenticity and reliability.

The speed of the steel cord is applied at $2 \mathrm{~mm} / \mathrm{s}$ through the ABAQUS finite element analysis software to extend at a constant speed and intercept $0.2 \mathrm{~s}$ when the steel cord $5 \mathrm{~mm}$ length side view and the steel cord in the middle section of the top view and ups, as shown in Figure 5. Steel cord at the same stretching speed, with the increase of lay length, the steel cord surface strand crosssectional stress gradually increased, core stock stress has no significant change, the steel cord cross-sectional stress distribution tends to be uniform when the steel cord lay length at $5 \mathrm{~mm}-9 \mathrm{~mm}$ range, the core stock stress is generally higher than the surface strand stress, and under the action of the stretch load, it can be seen from the top view and the elevation view that the stress of the face stock on the upper side of the load direction is much lower than the stress on the opposite side of the load direction. With the increase of lay length, the stress distribution of steel cord face share tends to be uniform, the stress concentration decreases, and the stress distribution of steel cord core share tends to be consistent with the surface strand stress distribution when the lay length reaches more than $11 \mathrm{~mm}$.

Through the postprocessing file, the analog pull of the steel cord and the corresponding time data are extracted to obtain the break force and break elongation of the steel cord under different lay length conditions, as shown in Figures 6 and 7, and with the increase of the lay length, $0.28+6 \times 0.26$ steel cord and $0.26+6 \times 0.24$ steel cord break force gradually increased. When the lay length is less than $9 \mathrm{~mm}$, the steel cord break force increases with the lay length, and the upward trend is more obvious; when the steel cord lay length is more than $9 \mathrm{~mm}$, the steel cord lay length of the lift steel cord break force is still an upward trend, but the trend gradually slows down. The fracture elongation trend is the opposite of the break force with the variation of the lay length. When the lay length is less than $9 \mathrm{~mm}$, steel cord break elongation shows a more obvious downward trend, and the drop trend slows down when the lay length exceeds $9 \mathrm{~mm}$. The pattern making and stretching test of the $7 \mathrm{~mm}$ lay length steel cord is carried out, and the results obtained from the simulation are compared and verified, as shown in Table 4 below, and it can be seen from the table that the simulation results of the steel cord simulation are the same as the actual measurements.

The pattern making and stretching test of the $7 \mathrm{~mm}$ lay length steel cord is carried out, and the results obtained from the simulation are compared and verified, as shown in Table 4 below, and it can be seen from the table that the simulation results of the steel cord simulation are the same as the actual measurements.

3.2. Spinning Loss. The difference between the actual strength value of the processed steel cord and the expected strength value is called spinning loss, and the commonly used calculation formula is

$$
\eta=\frac{\left(F_{0}+n \cdot F_{1}\right)-F}{F_{0}+n \cdot F_{1}},
$$

$\eta$ : loss $/ \% F_{0}$ : core stock single wire break force/N. $F_{1}$ : face stock single wire break force/N. $n$ : face share single silk quantity. F: steel cord break force/N.

The results of the simulation of $0.26+6 \times 0.24$ steel cords and $0.28+6 \times 0.26$ steel cords at different lay length are calculated by formula (1) As shown in Figure 8, when the steel cord lay length increases the spinning loss of steel cord slinging and the increase in the margin is inversely proportional, with the increase of the lay length, the spinning loss of the steel line is on a downward trend, the lay length is lower than $9 \mathrm{~mm}$ the decline trend is larger, higher than $9 \mathrm{~mm}$ when the downward trend gradually slows down.

3.3. Spinning Loss and Stress Analysis of Steel Cord Bran. Steel cord surface strands are spiral like and therefore more complex force faces stock line. Single wire tension F1 direction is the center line direction of the face stock, which can be broken down into vertical in the center direction of the face stock force $\mathrm{N}$, shear force, and stretch direction of $\tau$ and axial force $F_{\delta}$, as shown in Figure 9 below, wherein the stock edge angle and the ring length of the $\alpha$ margin $P$, radius $R$ formed by the triangular function relationship can be calculated by the formula corner size; the formula is as follows:

$$
\tan \alpha=\frac{P}{2 \pi R} .
$$

Steel cord load $F$ is mainly composed of core stock strand tension $F 0$, face stock strand tension axial split force $F_{\delta}$, shear force $\mathrm{N}$, and torque $\tau$ and axial split force $F_{1}$, the main formula is

$$
\begin{aligned}
F_{\delta} & =F_{1} \sin \alpha, \\
\tau & =F_{1} \cos ^{2} \alpha, \\
N & =F_{1} \cos \alpha \sin \alpha, \\
F & =F_{0}+6 \times\left[F_{\delta}+(\tau-N) \cos \alpha\right] .
\end{aligned}
$$

Steel cord torque and shear force is much lesser than the face tension $F_{1}$ axial split force, so the steel cord tensile strength $\mathrm{F}$ is mainly affected, and $\sin \alpha$ with the increase in the lay length of steel cord angle $\alpha$ gradually increased, so the tensile strength $\mathrm{F}$ with $\sin \alpha$ gradually increased, and the upward trend gradually slowed down.

$$
\eta=\frac{\left[F_{0}+n \cdot\left(F_{1} \sin \alpha+F_{1} \cos ^{3} \alpha+F_{1} \cos ^{2} \alpha \sin \alpha\right)\right]-F}{F_{0}+n \cdot\left(F_{1} \sin \alpha+F_{1} \cos ^{3} \alpha+F_{1} \cos ^{2} \alpha \sin \alpha\right)} .
$$

By the refined loss formula, the $0.26+6 \times 0.24$ steel cord and $0.28+6 \times 0.26$ steel cord stretching simulation experimental results were calculated, and the loss of the tanning system was greatly reduced, and the comparison of the original results was negligible, as shown in Figures 10 and 11 below. 


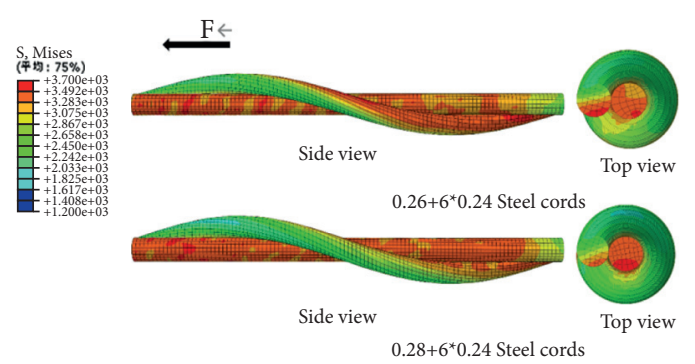

(a)

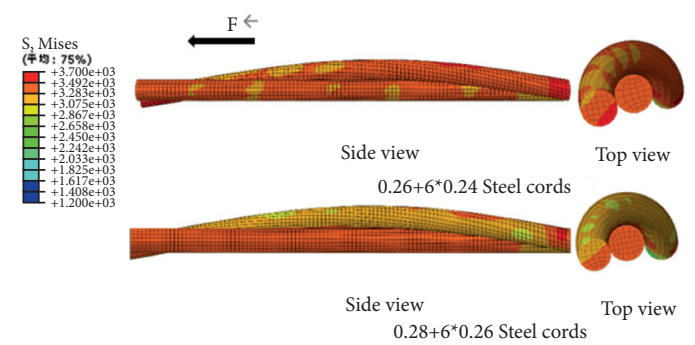

(c)

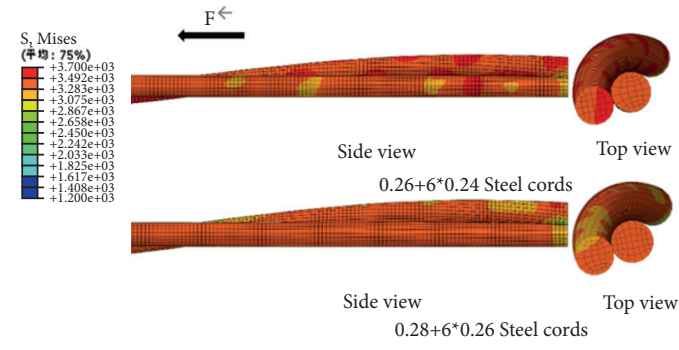

(e)
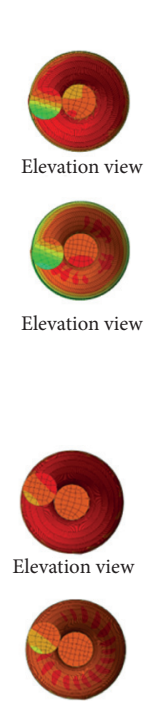

Elevation view

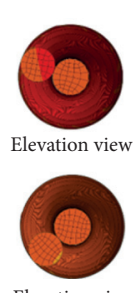

Elevation view

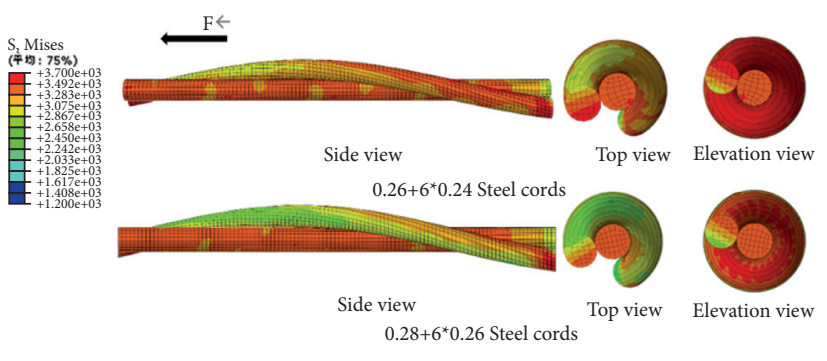

(b)

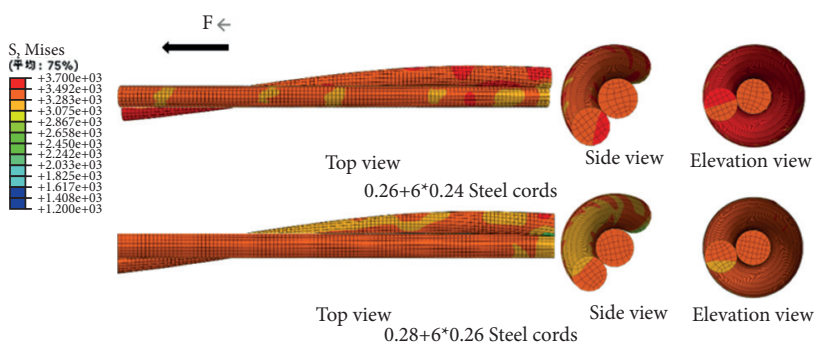

(d)

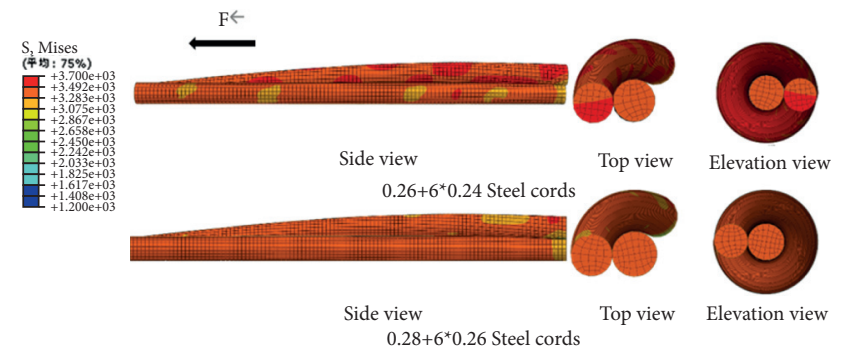

(f)

Figure 5: Different lay length steel cords missing the stress cloud map at $0.4 \mathrm{~mm}$ deformation. (a) $P=5 \mathrm{~mm}$; (b) $P=7 \mathrm{~mm}$; (c) $P=9 \mathrm{~mm}$; (d) $P=11 \mathrm{~mm}$; (e) $P=13 \mathrm{~mm}$; (f) $P=15 \mathrm{~mm}$.

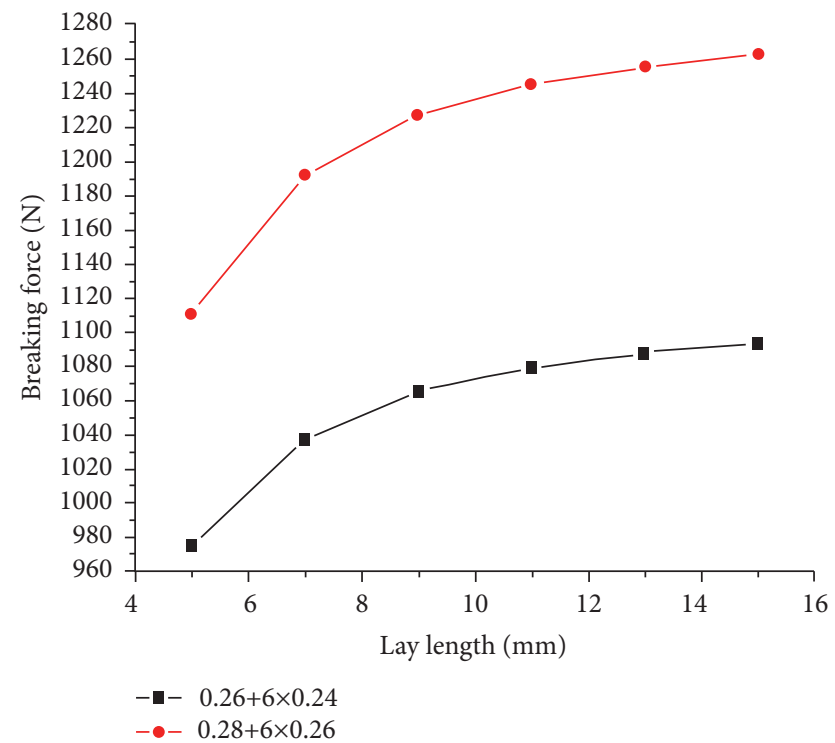

FIGURE 6: $0.26+6 \times 0.24$ steel cord and $0.28+6 \times 0.26$ steel cord breaking force change curve with lay length.

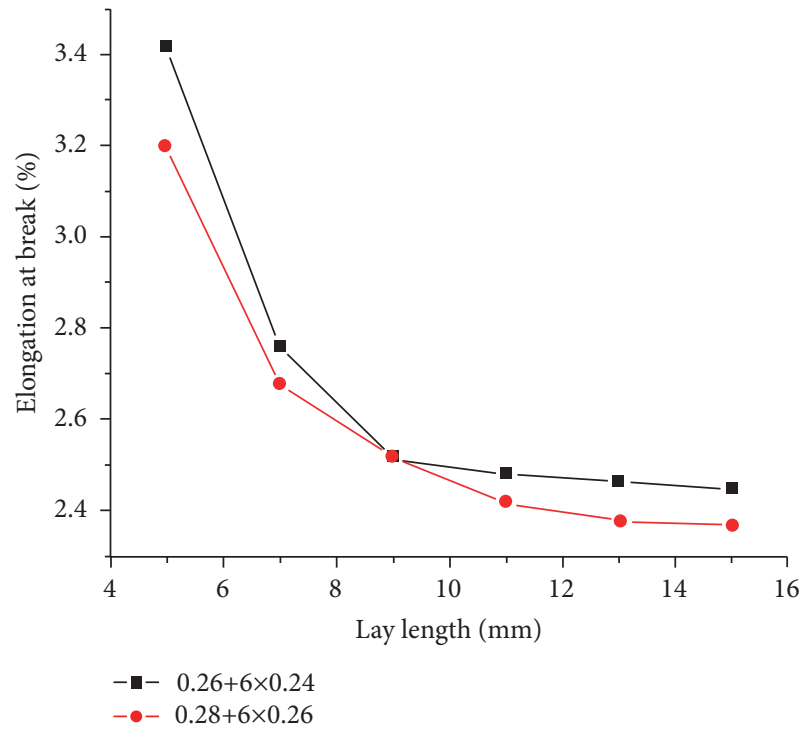

Figure 7: $0.26+6 \times 0.24$ steel cord and $0.28+6 \times 0.26$ steel cord elongation at break change curve with lay length. 
TABLE 4: Lay length p-7 mm steel cord break force simulation results compared with experimental results.

\begin{tabular}{lcc}
\hline Steel cord type $(\mathrm{mm})$ & Simulated simulation break force $(\mathrm{N})$ & Breaking force test $(\mathrm{N})$ \\
\hline $0.26+6 \times 0.24$ & 1037 & 967 \\
$0.28+6 \times 0.26$ & 1192 & 1214 \\
$0.26+6 \times 0.24$ & 1037 & 967 \\
\hline
\end{tabular}

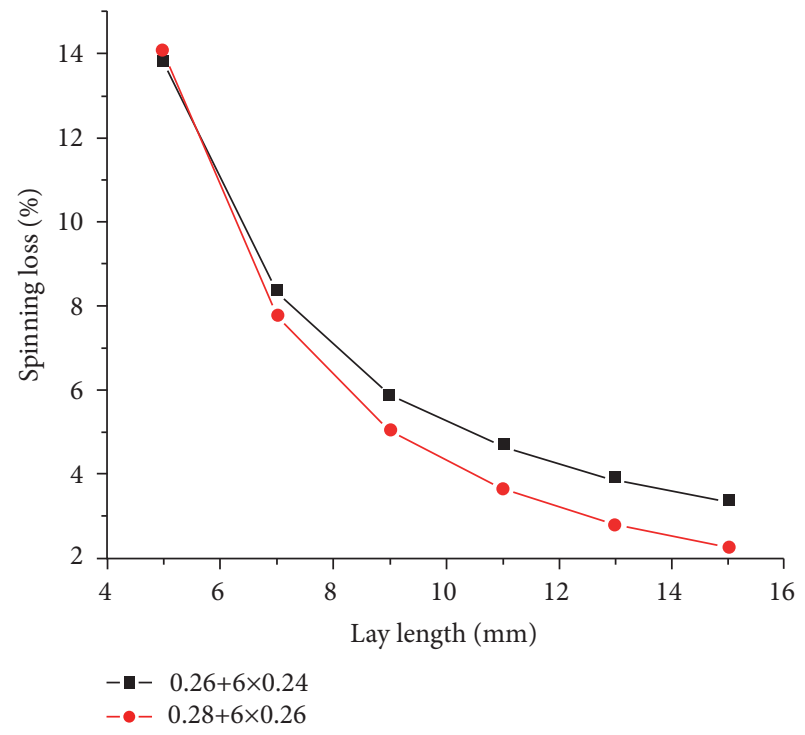

FIGURE 8: The spinning loss of steel cords varies with the lay length.

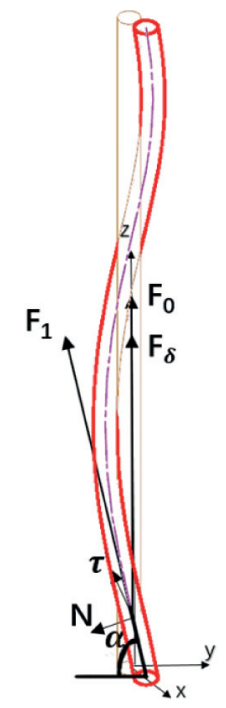

FIgURE 9: Steel cord stress decomposition.

\section{Conclusions}

The lay length is one of the most important factors affecting the tensile properties of steel cords. This article is mainly based on other scholars' research on steel cord modeling and adjusts and studies the process parameters in steel cord production through finite element analysis. Based on the finite element analysis, the steel wire used in the steel cord and the finished steel cord with $7 \mathrm{~mm}$ lay length passed the finite element analysis results and the experimental test

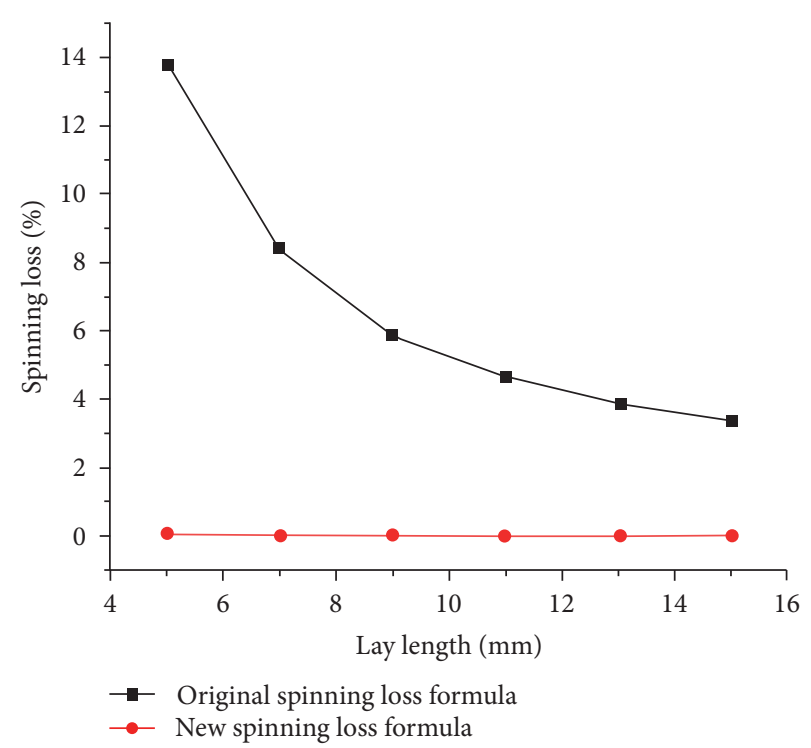

FIGURE 10: $0.26+6 \times 0.24$ steel cord new and old formula to make a spinning loss result comparison.

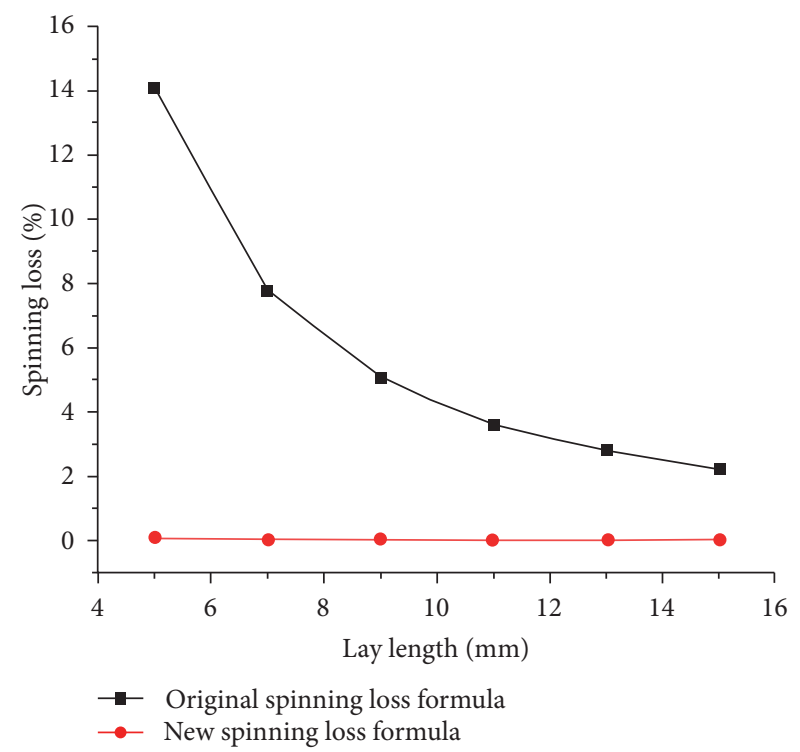

FIgURE 11: $0.28+6 \times 0.26$ steel cord new and old formula to make a spinning loss result comparison.

results. By comparison, the accuracy of the value was verified, and the tensile finite element analysis of two types of steel cords with different lay lengths was carried out to determine the influence of the lay length on the performance of the steel cord. With the increase of the lay length, the steel curtain of the wire breaking force is increased, the stress concentration is gradually reduced, and the cross-sectional 
stress distribution of the steel cord is more uniform. However, the upward trend has gradually slowed down. It can be seen that increasing the twist pitch of steel cords can improve the overall performance of steel cords to a certain extent, but the two are not linear. The above conclusions are not only for the choice of twist pitch process parameters in production but it plays an auxiliary role with adjustment and also plays a guiding role in the research of other production process parameters of steel cord, such as the diameter of different strands and the cross-sectional shape of strands.

\section{Data Availability}

The FEM data used to support the findings of this study are included within the article.

\section{Conflicts of Interest}

The authors declare that there are no conflicts of interest regarding the publication of this paper.

\section{References}

[1] W. Chen, L. Li, and J. S. Li, "Research on tension distribution of wire and friction among wires in strand of wire rope," Mining \& Processing Equipment, vol. 48, no. 5, pp. 26-32, 2020.

[2] K. Robert and U. Malgorzata, "Analysis of fatigue life of the steel cord used in tires in unidirectional and bidirectional bending," Procedia Structural Integrity, vol. 13, 2018.

[3] W. X. Qin, "Necessity of improving mathematical skill in study of wire rope theory," Metalworking Production, vol. 446, no. 1, pp. 5-9+13, 2012.

[4] J. Zhou, Z. Zhou, L. Yao, R. Dai, W. Chao, and Z. Jiang, "Influence of different lay length of wire rope on mechanical properties," Metalworking Production, vol. 45, no. 4, pp. 6-9, 2019.

[5] G. Sun, Z. Shen, H. Zhao, Z. Ma, and S. Huang, "Research on periodicity of wire rope structure," Metalworking Production, vol. 46, no. 3, pp. 1-3, 2020.

[6] M. J. Kyoung, W. K. Kee, and H. K. Jang, "Global-local finite element analysis for predicting separation in cord-rubber composites of radial truck tires," Open Journal of Modelling and Simulation, vol. 07, no. 4, 2019.

[7] T. He, Z. R. Li, and Y. Wang, "Finite element analysis for sliding abrasion of tread blocks of radial tire," Engineering MeChanics, vol. 27, no. 7, pp. 237-243+249, 2010.

[8] Z. J. Shen, W. X. Qin, and Y. B. Yu, "Calculation and application of angle cycle of secondary spiral steel wire in wire rope," Metalworking Production, vol. 64, no. 8, pp. 481-484, 2017.

[9] X. Y. Long, X. G. Li, and H. B. Long, "Analysis of influence of multiple steel cords on splice strength," Journal of Adhesion Science and Technology, vol. 32, no. 24, 2018.

[10] G. Wang, R. Zhao, J. Sun, and H. Zhang, "The CAD of wire rope structure based on differential geometry," Journal of Huazhong University of Science and Technology (Nature Science Edition), no. 6, pp. 4-6, 2003.

[11] G. L. Wang, J. F. Sun, and H. O. Zhang, "Spatial geometric model and finite element analysis of wire rope twisting," Journal of Applied Mechanics, vol. 60, no. 3, pp. 82-86+162, 2003.
[12] C. Erdonmez and C. E. Imrak, "A finite element model for independent wire rope core with double helical geometry subjected to axial loads," Sadhana, vol. 36, no. 6, pp. 995-1008, 2011.

[13] C. Imrak and C. Erdönmez, "On the problem of wire rope model generation with axial loading," Mathematical and Computational Applications, vol. 15, no. 2, pp. 259-268, 2010.

[14] C. Erdönmez and C. E. İmrak, "Wire strand and IWRC modeling and contact analysis using finite elements," Key Engineering Materials, vol. 450, pp. 115-118, 2011.

[15] X. Y. Wang, X. B. Meng, J. X. Wang, and K. Gao, "Implementation of mathematical modeling for wire rope strands," Advanced Materials Research, vol. 608 609, pp. 1769-1772, 2013.

[16] X. Y. Wang, X. B. Meng, J. X. Wang, Y. H. Sun, and K. Gao, "Mathematical modeling and geometric analysis for wire rope strands," Applied Mathematical Modelling, vol. 39, no. 3-4, pp. 1019-1032, 2015.

[17] L. Xiang, H. Y. Wang, Y. Chen, Y. J. Guan, and L. H. Dai, "Elastic-plastic modeling of metallic strands and wire ropes under axial tension and torsion loads," International Journal of Solids and Structures, vol. 129, 2017.

[18] X. Li, X. Long, Z. Shen, and C. Miao, "Analysis of strength factors of steel cord conveyor belt splices based on the FEM," Advances in Materials Science and Engineering, vol. 2019, no. 2, pp. 1-9, 2019.

[19] D. Olchówka, A. Rzeszowska, L. Jurdziak, and R. Błażej, "Statistical analysis and neural network in detecting steel cord failures in conveyor belts," Energies, vol. 14, no. 11, p. 3081, 2021.

[20] J. F. Sun, A Dissertation Submitted in Partial Fulfillment of the Requirements for the Degree of Doctor of Philosophy in engineering, Huazhong University of Science and Technology, Wuhan, China, 2004.

[21] X. Y. Wang, Paremetric Modeling Method of Wire Ropes and the Analysis of Their Mechanical properties, Jilin Univer-sity, Changchun, China, 2017.

[22] Z. H. Chen, L. L. Guo, H. B. Liu, and H. Chen, "Finite element study of behaviour and interface force conditions of locked coil wire rope under axial loading," Construction and Building Materials, vol. 272, 2021.

[23] W. J. Zhang, X. F. Yuan, C. Chen, and L. Yang, "Finite element analysis of steel wire ropes considering creep and analysis of influencing factors of creep," Engineering Structures, vol. 229, Article ID 111665, 2021.

[24] Z. Shen, W. Qin, D. Li, G. Sun, and H. Zhao, "Study on mathematical conditions for existence of turning period of double spiral steel wire in strand," Metalworking Production, vol. 46, no. 04, pp. 11-19, 2020. 